\section{Theferences}

1. J. Frenkel: Jnl. Phys. U.S.S.R. (1945) 9, No. 5, 385.

2. A. J. Shaler and J. Wulff: Ind. Eng. Chem. (1948) 40, 838.

3. B. Ya. Pines: Jnl. Tech. Phys., (1946) 16, No. 6, 737.

4. R. F. Mehl: Trans. AIME (1936) 122, 11.
5. A. Samoilovich: Acta Physicochimica U.S.S.R., (1946) $21,13$.

6. F. N. Rhines and R. F. Mehl: Trans. AIME (1938) 128, 285.

7. B. V. Rollin: Phys. Rev. (1931) 55, 231.

8. J. Steigman, W. Shockley and F. C. Nix; Phys. Rev. (1939) 56, 13.

9. C. L. Raynor, L. Thomassen and L. J. Rouse: Trans. Am. Soc. Met. (1942) 30, 313.
10. M. S. Maier and H. R. Nelson: Trans AIME (1942) 147, 39.

11. W. A. Johnson: Trans. AIME (1941) 143, 107.

12. W. Schottky: Ztsch. Phys. Chem. B. (1935) 29, 335.

13. J. Cichocki: Jnl. de Phys. (VII) (1938) 9, 129.

14. F. Seitz: The Modern Theory of Solids. (1940) McGraw-Hill.

\title{
A Simple Constant Stress Creep Test
}

\section{J. C. FISHER* and R. P. CARREKER*}

Cheep tests are normally constant load tests. Such tests approximate some types of service conditions and therefore are justified from the engineering point of view. Coupled with this consideration is the advantage of simplicity inherent in constant load tests, as contrasted with the comparatively complex requirements of a constant stress test. It is not surprising that the vast majority of creep tests reported are of the constant load type.

Despite the enormous amount of accumulated creep test data, plastic flow is by no means completely understood. The widespread use of constant load tests is at least partly responsible for this lack of understanding. Any attempt to analyze deformation must involve the more fundamental quantity stress, rather than load. It is possible to predict constant load behavior from known constant stress data, but the reverse is much more difficult.

When a metal specimen elongates, as in a creep test, the cross section decreases, maintaining constant volume. Thus

$$
\frac{A}{A_{0}}=\frac{l_{0}}{l}
$$

For a constant stress test the force on the specimen must be decreased as the cross section decreases, that is, this force must be inversely proportional to the elongation of the specimen. Andrade has described three methods of obtaining the constant stress condition, ${ }^{1-3}$ each of which is relatively complex. The most recent proposal, ${ }^{3}$ suggests a major simplification which maintains the simplicity of the constant load test while approximating quite closely the desirable condition of constant stress. Andrade's device is admittedly more accurate but the method described below has definite advantages.

Consider a specimen in the form of a

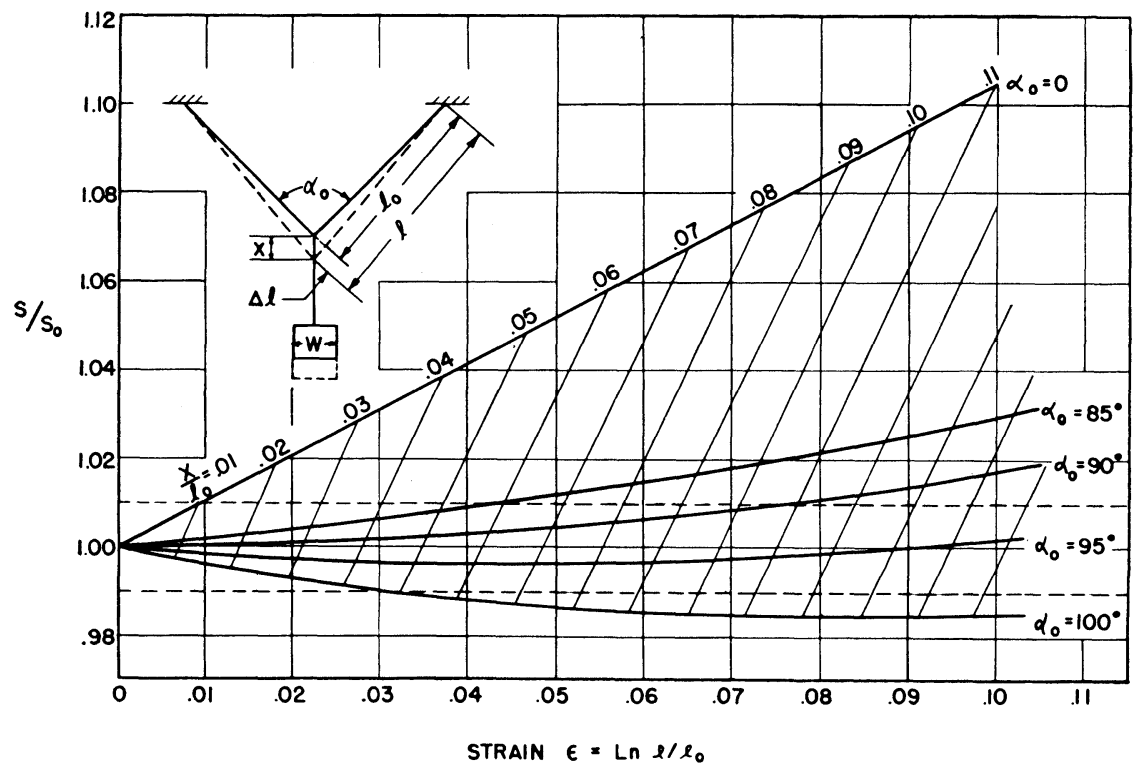

FIG 1-Variation of stress with initial angle.

"V" supported at its ends. If a weight be applied at the vertex of the angle, the stress in each leg of the " $V$ " is

$$
S=\frac{w}{z} \cdot \sec \frac{\alpha}{z} \cdot \frac{1}{A} .
$$

If this stress causes an elongation $\Delta l$ in each leg of the "V," the angle decreases from $\alpha_{0}$ to a smaller angle $\alpha_{1}$. The quantity sec $\frac{\alpha}{z}$ thus decreases with specimen elongation while the quantity $1 / A$ increases. By selecting proper initial conditions it should be possible to hold $S / S_{0}$ very nearly constant at unity.

The proper initial conditions are realized when $\alpha_{0}$ is made equal to approximately $90^{\circ}$. Fig 1 compares the ratios of $S / S_{0}$ for $\alpha_{0}=85,90,95,100^{\circ}$, with $\alpha_{0}=0$, that is, a straight speci-

Technical Note No. 10 E. Manuscript received October 13, 1948. * General Electric Co., Schenectady, N. Y.

1 References are at the end of the paper. men, for true strains up to $\epsilon=0.10$. It may prove convenient to measure $X$, the movement of the vertex, rather than the true elongation $\Delta l$. Contour lines of $X / l_{0}$ are also plotted in Fig 1 .

The method for obtaining constant stress described above is especially suited to the testing of small wires, but may easily be extended to rods of any diameter through the use of a suitable grip which serves as the vertex joining two identical rods forming the legs of the "V."

\section{References}

1. E. N. da C. Andrade: On the Viscous Flow in Metals, and Allied Phenomena. Proc. Roy. Soc., A, 84, 1 , (1910-11).

2. E. N. da C. Andrade and B. Chalmers: The Resistivity of Polycrystalline Wires in Relation to Plastic Deformation, and the Mechanism of Plastic Flow. Proc. Roy. Soc., A, 138, 348, (1932).

3. E. N. da C. Andrade: A New Device for Maintaining Constant Stress in a Rod Undergoing Plastic Extension. Proc. Phys. Soc., 60, (3), 304, (March, 1948). 